\title{
Anàlisi del contingut en calci de la llet
}

\author{
Marc Abella, Albert Baenas, Yolanda Fernández \\ Institut Mercè Rodoreda, l'Hospitalet de Llobregat \\ yfernand@xtec.cat
}

Es presenta un treball de recerca de segon de Batxillerat on s'han provat diferents tècniques analítiques per determinar el contingut en calci d'una llet comercial. Combinant diferents mètodes s'ha aconseguit trobar una forma ràpida, senzilla $i$ eficaç de valorar el contingut en calci.

Paraules clau: treball de recerca, llet, calci, anàlisi química

\section{Introducció}

La llet és probablement un dels aliments més importants al llarg de la vida de la majoria de persones. Especialment durant la infància, l'adolescència i posteriorment la vellesa, la llet ens aporta bona part dels nutrients necessaris, cosa que la fa gairebé imprescindible en la nostra nutrició.

L'objectiu principal d'aquest treball ha estat trobar la concentració d'algun d'aquests nutrients en llets de vaca comercials, tot utilitzant protocols més o menys senzills que es poguessin realitzar en un laboratori escolar. Per aquest motiu hem escollit el calci.

Actualment les llets comercials no enriquides contenen 120 parts per milió (ppm) mentre que en les enriquides s'eleva a 160 ppm.

Hem aplicat diferents procediments per determinar el contingut en calci i poder-lo comparar amb l'etiquetat. Aquests procediment són:

1) Determinació del calci per gravimetria després de la destrucció de la matèria orgànica

2) Determinació de calci per permanganimetria

3) Determinació del calci per gravimetria de precipitació

4) Valoració del calci mitjançant EDTA (àcid etilendiaminotetraacétic)

Finalment hem elaborat un "kit" que permet distingir entre una llet enriquida i una de no enriquida en calci amb un protocol molt senzill.

\section{Determinació del calci per gravimetria després de la des- trucció de la matèria orgànica}

Aquest procediment es basa en el fet que la llet sencera conté aproximadament entre 110 i 120 grams de matèria orgànica (proteïnes, hidrats de carboni i greixos) per litre. Teòricament, un cop eliminada tota la matèria orgànica ens hauríem de quedar amb els minerals de la llet, dels quals el calci n'és el més abundant. Es tracta, doncs, de destruir la matèria orgànica amb una barreja d'àcid sulfúric i d'àcid nítric comercial i formar, al mateix temps, sulfat de calci. Un cop format, només ens quedaria realitzar una filtració i pesar-ho per saberne la quantitat.

A la pràctica, un cop afegits els dos àcids dins el vas es produeix una reacció molt exotèrmica que allibera compostos de nitrogen tòxics (fig. 1).

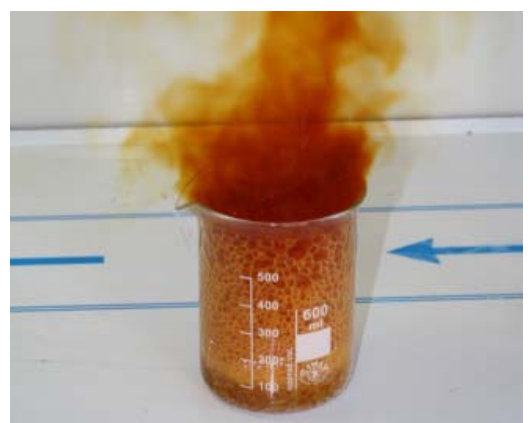

Figura 1. Reacció exotèrmica amb alliberament de compostos de nitrogen. 
Després de deixar reposar el resultat durant sis dies perquè es produeixi la sedimentació del sulfat de calci format durant aquest procés, s'ha observat que en el vas s'havia format una mescla heterogènia molt viscosa de color negre, difícil de filtrar. Per aquest motiu hem optat per descartar aquest mètode.

\section{Determinació del calci per permanganimetria}

Aquest mètode serveix per valorar ions que poden precipitar amb una substància reductora. Aquest no és un mètode específic per a la llet, però és prou senzill com per intentar de veure si funciona.

A $20 \mathrm{~mL}$ de llet hem afegit uns $80 \mathrm{~mL}$ d'aigua destillada i unes gotes de l'indicador vermell de metil: la dissolució no canvi de color. Hi hem afegit àcid clorhídric fins que la dissolució pren color rosa. Afegim llavors 40 gotes més i ho portem a ebullició.

A continuació hem afegit $25 \mathrm{~mL}$ de solució d'àcid oxàlic al 5\% i molt lentament una solució d'hidròxid d'amoni fins que la barreja s'ha tornat groga. En aquest moment, precipita un compost de color blanc: l'oxalat de calci, que cal deixar reposar durant 30 minuts.

El filtrat ha resultat un procés molt lent tot i ferho amb una placa filtrant i bomba de buit (fig 2).

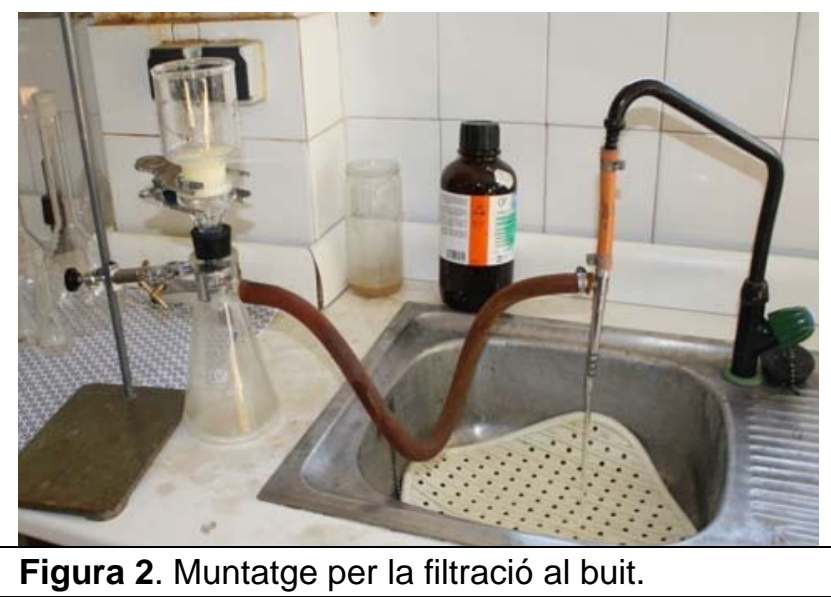

Un cop obtingut el sòlid hem afegit $10 \mathrm{~mL}$ d'àcid sulfúric calent i hem valorat els ions oxalat amb permanganat de potassi $0,02 \mathrm{M}$, produint-se les reaccions:

$$
\mathrm{Ca}\left(\mathrm{C}_{2} \mathrm{O}_{4}\right)+\mathrm{H}_{2} \mathrm{SO}_{4} \rightarrow \mathrm{H}_{2}\left(\mathrm{C}_{2} \mathrm{O}_{4}\right)+\mathrm{CaSO}_{4}
$$

$$
\begin{gathered}
5 \mathrm{C}_{2} \mathrm{O}_{4} \mathrm{H}_{2}+2 \mathrm{MnO}_{4}^{-}+16 \mathrm{H}^{+} \rightarrow \\
\rightarrow 10 \mathrm{CO}_{2}+10 \mathrm{H}^{+}+2 \mathrm{Mn}^{2+}+8 \mathrm{H}_{2} \mathrm{O}
\end{gathered}
$$

\section{Determinació del calci per gravi- metria de precipitació}

A $25 \mathrm{~mL}$ de llet hem afegit $25 \mathrm{~mL}$ d'àcid tricloracètic, formant-se dues fases: una fase líquida, el sèrum, on es localitza el calci, i una segona fase sòlida de color blanc d'aspecte pastós on es localitzen la resta de components de la llet, majoritàriament proteïnes, glúcids i greixos.

Hem filtrat amb un filtre de plecs i al filtrat li hem afegit aigua destil.lada i l'hem escalfat a $80^{\circ} \mathrm{C}$. Hem afegit després $15 \mathrm{~mL}$ d'oxalat de sodi 0,05 $\mathrm{M}$ i amoníac per aconseguir un pH entre 8 i 9.

En aquest moment precipita l'oxalat de calci, que es filtra amb una placa filtrant, tarant la placa prèviament. Es deixa a l'estufa a $110^{\circ} \mathrm{C}$ i es pesa.

\section{Valoració del calci mitjançant ED- TA (àcid etilendiaminotetraacètic)}

La valoració amb EDTA no s'aplica per quantificar el calci de la llet; és un mètode utilitzat per determinar la duresa total de l'aigua deguda a la presència de sals de $\mathrm{Ca}^{2+} \mathrm{i} \mathrm{Mg}^{2+}$.

Tot $\mathrm{i}$ això, ens hem adonat que en el procediment anterior, just després de separar la fase sòlida de la fase líquida, que és el sèrum, s'obtenia un líquid prou transparent. Hem pensat que, en aquest moment, podríem realitzar la valoració amb EDTA.

Tot $\mathrm{i}$ que aquest mètode mesura el ions $\mathrm{Ca}^{2+} \mathrm{i}$ $\mathrm{Mg}^{2+}$, com que la concentració de $\mathrm{Mg}^{2+}$ es situa aproximadament en només $8 \mathrm{mg}$ cada $100 \mathrm{~mL}$ de llet, l'hem considerat prou adequat.

Es tracta doncs d'aplicar una combinació de dos mètodes d'anàlisi: tractament $\mathrm{amb}$ àcid tricloracètic i valoració amb EDTA.

Un cop s'obté la part líquida, el sèrum, en la qual es troba el calci, hem procedit a realitzar una valoració amb EDTA amb negre d'ericrom-T (NET) com a indicador a $\mathrm{pH}=10$. EI NET reacciona $\mathrm{amb}$ el calci formant $[\mathrm{Ca}(\mathrm{NET})]^{2+}$, un compost complex de color rosat.

A l'anar afegint l'EDTA aquest va desplacant al NET, formant el compost $[\mathrm{Ca}(\mathrm{EDTA})]^{2+}$, més estable que el primer, de manera que a mesura que anem afegint l'EDTA, el calci es va alliberant del NET per formar aquest compost amb l'EDTA. 
Un cop alliberat tot el NET (és a dir, un cop ja ha reaccionat tot el calci), la dissolució passa a ser del color blau original del NET, color que ens indica el punt final de la valoració (fig. 3).

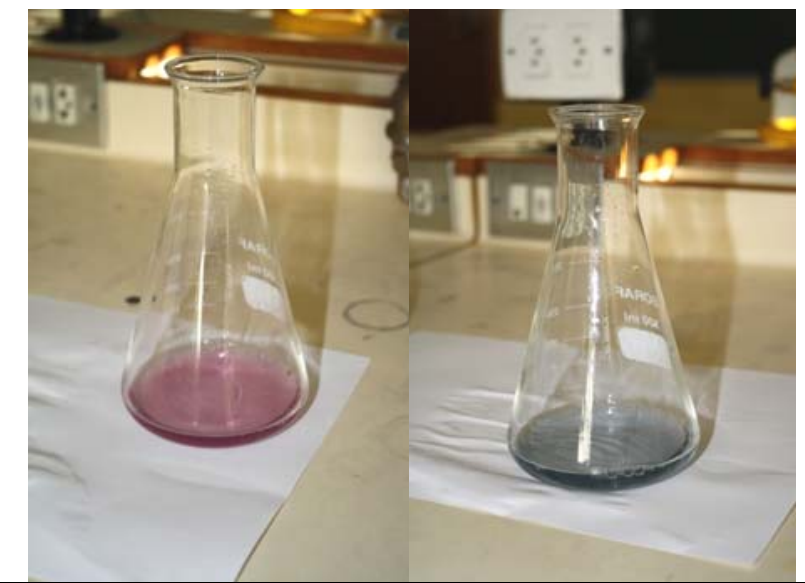

Figura 3. Quan afegim el NET, obtenim (esquerra) un compost de color rosat. En acabar la valoració (dreta), la dissolució adquireix color blau.

\section{Comparació de resultats}

En la figura 4 es mostren les concentracions de calci obtingudes amb els tres darrers mètodes per als dos tipus de llet: normal i enriquida.

S'ha realitzat cada anàlisi tres vegades.

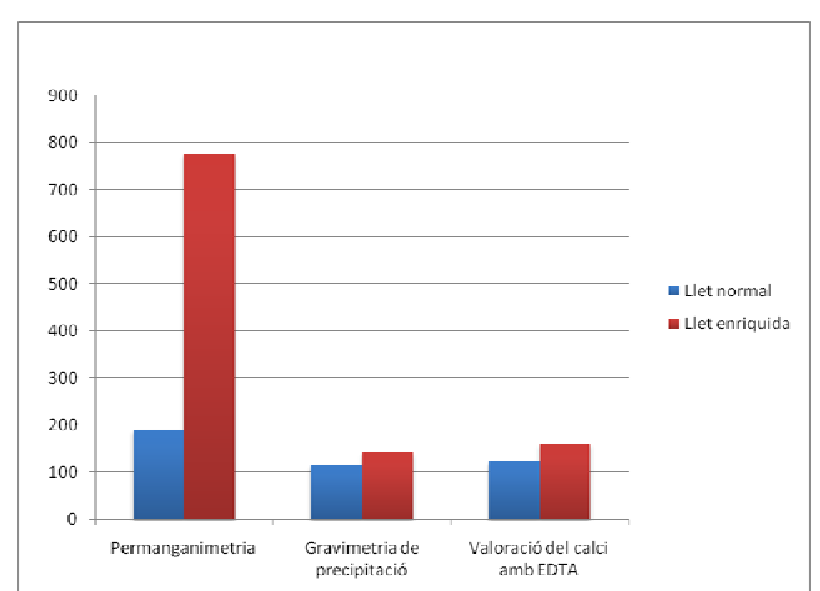

Figura 4. Comparació dels resultats obtinguts amb els diferents mètodes.

Es pot observar que la permanganimetria sobreestima el contingut en calci. Els resultats més acurats (més a prop de 120 mg / 100 mL i 160 mg / $100 \mathrm{~mL}$ ) s'obtenen amb el mètode combinat (addició d'àcid tricloracètic i valoració amb EDTA).

\section{"Kit" d'anàlisi de la quantitat de calci en la llet}

Un cop hem comprovat l'efectivitat de la combinació dels dos mètodes, vam pensar en provar la segona part sense fer prèviament la primera. Volíem comprovar si utilitzant només l'EDTA i el NET podríem fer un petit protocol per trobar la concentració del calci en la llet, que fos molt senzill i ràpid d'utilitzar. L'únic problema que podríem tenir és que, a causa de la poca transparència de la llet, no es pugui apreciar el canvi de color.

Aquest "kit" el vam dissenyar per tal que qualsevol persona pogués saber si una llet conté o no el calci que diu tenir. D'aquesta manera havia de ser un protocol que es fes sense eines de laboratori o amb les mínimes possibles. Per aquest motiu aquest "kit" no necessita provetes ni vasos de precipitats sinó simplement tres flascons amb comptagotes contenint (fig. 5):

- dissolució reguladora de $\mathrm{pH}=10\left(\mathrm{NH}_{3} \mathrm{i} \mathrm{NH}_{4}{ }^{+}\right)$

- EDTA (àcid etilendiaminotetraacètic) 0,05 M

- NET (negre d'ericrom-T)

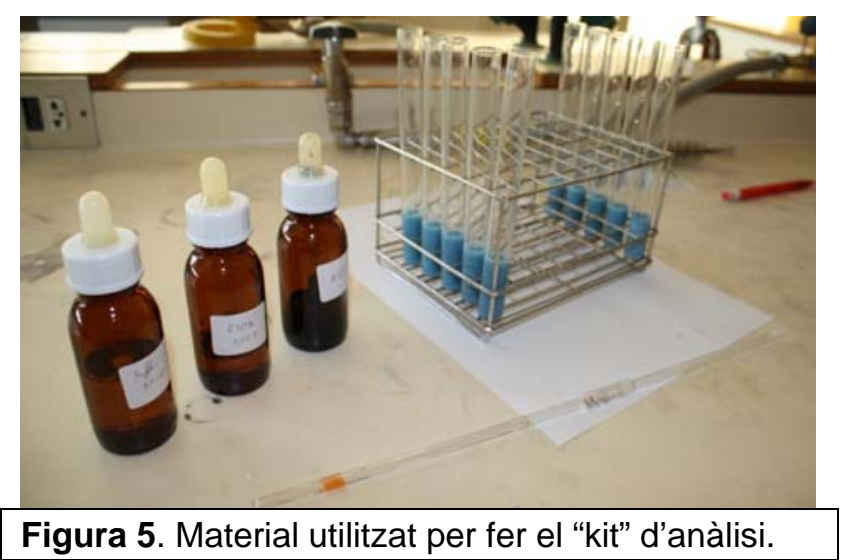

A la mostra de llet (uns $2 \mathrm{~mL}$ ) cal afegir-li 4 gotes de dissolució reguladora i a continuació 2 gotes de NET. La llet adquireix una coloració lila. Seguidament cal anar afegint gotes de la dissolució d'EDTA. Si la llet és normal, amb 20 gotes de la dissolució el color canvia a blau. Si la llet és enriquida aquest canvi no es produeix (es necessitaria un $33 \%$ més de reactiu, doncs conté un 33\% més de calci).

D'aquesta forma es poden distingir les llets normals de les enriquides. Ho hem comprovat amb llets de diferents marques (fig. 6), essent efectiu el mètode per a totes elles. 


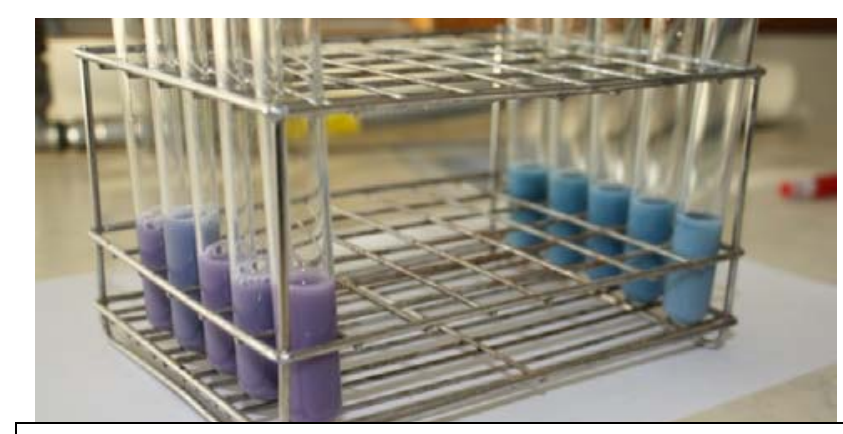

Figura 6. En afegir les 20 gotes d'EDTA, només les llets no enriquides (dreta) completen la reacció i donen coloració blava.

\section{Conclusions}

Després de provar diferents mètodes d'anàlisi del contingut de calci en la llet, arribem a la conclusió que els millors resultats s'obtenen combinant el tractament $a m b$ àcid tricloracètic $i$ valorant $a m b$ EDTA.

També hem aconseguit un mètode senzill $\mathrm{i}$ visual per saber el contingut en calci de qualsevol llet comercial.

\section{Bibliografia}

ABELLA, Marc i BAENAS, Albert (2009) Estudi dels components de la llet. Anàlisi del calci. Treball de recerca de segon de Batxillerat, sense publicar. 